\title{
Design and Implementation of Firing Circuit for Single- Phase Converter
}

\author{
Tirtharaj Sen, Pijush Kanti Bhattacharjee, Member, IACSIT, Manjima Bhattacharya
}

\begin{abstract}
The theme of the paper is to design and implement the firing circuit for a converter. The necessity of getting synchronized firing pulses for the gate of the thyristor is discussed. Out of many variety of firing circuits available, the ideas behind are the two most popularly used control circuits that are namely using ramp signal and using cosine signal. It shows how a cosine controls scheme work. Detail description and functioning of each block is explained along with the waveforms at the output of the blocks. Experimental results obtained from oscillographic displays at important points of the circuits are included. In this paper, we fabricate a hardware circuit which implements the cosine control technique, test the circuit and also check that desired gate pulses for the thyristors.
\end{abstract}

Index Terms-Thyristors or Silicon Controlled Rectifiers (SCRs), Bipolar Junction Transistors (BJTs), Metal Oxide Semiconductor Field Effect Transistors (MOSFETs), Insulated Gate Bipolar Transistors (IGBTs), Single Phase Converter, Comparator, Monoshot, Exclusive Or gate, SR Flip Flop, 555 Timer.

\section{INTRODUCTION}

Thyristors or Silicon Controlled Rectifiers (SCRs) [1]-[5] are widely used as a switching device in the medium and large power levels starting from few kilowatts to several mega watts at voltage levels of few hundred to several kilo volt levels. Bipolar Junction Transistors (BJTs) and Metal Oxide Semiconductor Field Effect Transistors (MOSFETs) although have very fast switching characteristics compared to SCRs, their uses are limited to medium power levels at few hundred volts.

Insulated Gate Bipolar Transistors (IGBTs) are switching devices which have positive points over the MOSFETs and thyristors. However, their higher cost and inability to work at very high voltages makes SCR a better choice even today,

Manuscript received November 30, 2010; revised March 12, 2011.

Tirtharaj Sen is with the Department of Electrical Engineering, Asansol Engineering College, Kanyapur, Vivekananda Sarani, Asansol, Burdwan713305. He was an Ex Assistant Professor \& Head, Dept. of E.E, Bengal Institute of Technology and Management. He has twelve years Industrial experience and nearly six years teaching experience. (Phone: +919432851324, email: tirtha.bitm@gmail.com).

Pijush Kanti Bhattacharjee is with the Department of Electronics and Telecommunication Engineering, Assam University, [A Central University], Silchar, Assam, Pin-788011, India. He was an Ex Asssitant Director in Department of Telecommunications (DoT), Government of India, India. He has possessed vast working experience in the field of Telecommunications including Mobile Communications, Image Processing, VLSI, Nanotechnology, Management etc. during last 30 years.(phone: +9133-25954148, email: pijushbhatta_6@hotmail.com).

Manjima Bhattacharya is with Electrical Engineering Department at Murshidabad College of Engg. \& Technology, Berhampore, West Bengal, India. (phone: +91-8016707785, email: tunambhattacharya@gmail.com). so far as line commutated converters are concerned. In this paper we have designed to implement low cost firing circuit for a single phase line commuted converters.

\section{A. Thyristor \& its conduction}

A thyristor or SCR is a four layer device having three junctions J1, J2 and J3. Essentially three terminals named anode, cathode and gate are available as shown in Fig. 1 (below) for external connections. Under the conditions a thyristor either conduct or not conduct, i.e., it allows current either to flow or not, is pictorially depicted in Fig. 1. A thyristor will be in reverse blocking mode if $\mathrm{V}_{\mathrm{AK}}<0$, irrespective of the fact that a gate pulse is present or not. On the other hand the thyristor is said to be in the forward blocking mode, when $\mathrm{V}_{\mathrm{AK}}>0$ in absence of any gate pulse, some current will flow through the thyristor. In case of the thyristor is turning on either by exceeding the forward break-over voltage or by applying a gate pulse between gate and cathode, called forward conduction mode.

Therefore if we want to use a SCR as a switching device [1]-[5], we must ensure that appropriate gate pulse is supplied between gate and cathode at desired instant of time.

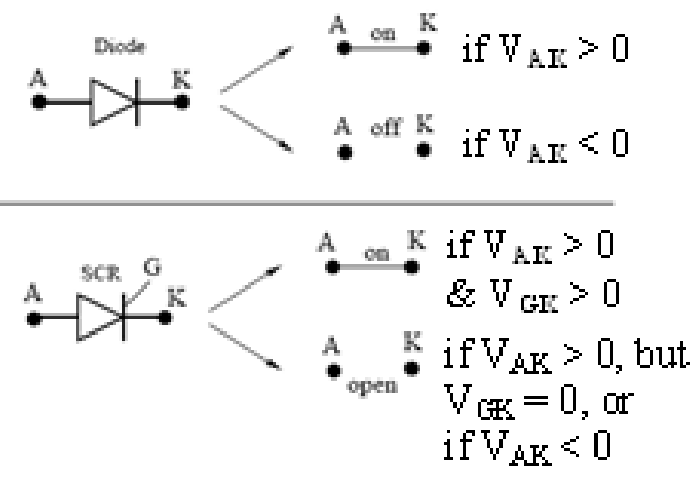

Fig. 1. Symbols for Diode and Thyristor

Some important values of a thyristor is given below:

Voltage rating- $230 \mathrm{~V}$

Current rating- $20 \mathrm{~A}$

Turn on time $\left(\mathrm{T}_{\mathrm{ON}}\right)-1$ to $2 \mu \mathrm{sec}$

Turn off time $\left(\mathrm{T}_{\mathrm{OFF}}\right)$ - about $70 \mathrm{~mA}$ to $100 \mathrm{~mA}$ current

Pulse of duration $>$ TON

Conduction voltage drop- about $1.2 \mathrm{~V}$

The number of degrees from the beginning of the cycle when the SCR is gated or switched on is referred to as the firing angle, symbol as $\alpha$, and the number of degrees that the SCR remains conducting is known as the conduction angle.

\section{B. Line Commutated Converters}

Conversion of line frequency $(50 \mathrm{~Hz})$ a.c. to d.c. [1]-[5] is carried out either by using a single phase bridge converter using four thyristors or 3-phase converter using six thyristors. A single phase fully controlled bridge with four 
thyristors is shown in Fig. 2. Appropriate pulses between the gates and cathodes of the thyristors $\mathrm{T} 1$ to $\mathrm{T} 2$ are to be supplied with a provision to vary the firing angle $\alpha$.

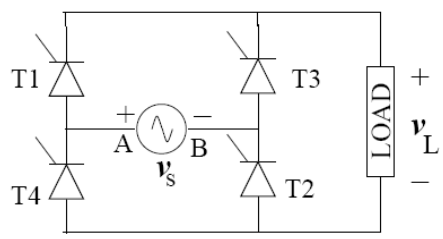

Fig. 2. Fully Controlled Converter

With reference to the single phase converter circuit shown in Fig. 2, we note that when $\mathrm{V}_{\mathrm{AB}}>0$ or positive, two diagonally opposite thyristors $\mathrm{T} 1$ and $\mathrm{T} 2$ are forward biased and other two thyristors $\mathrm{T} 3$ and $\mathrm{T} 4$ are reversed biased. Therefore during intervals (i.e. $0^{0}$ to $180^{\circ}$ ) gate pulses are simultaneously applies to $\mathrm{T} 1$ and $\mathrm{T} 2$, both start conducting and load voltage $\mathrm{V}_{\mathrm{L}}=\mathrm{V}_{\mathrm{AB}}$ and also $\mathrm{T} 3$ and $\mathrm{T} 4$ are reversed biased and cannot conduct at that period of time and vice versa (When T3 and T4 are switched on, $\mathrm{V}_{\mathrm{L}}=\mathrm{V}_{\mathrm{BA}}$ ).

\section{Necessity of getting synchronizing pulses}

Typical waveform of the supply voltage, gate pulses necessary are shown in Fig. 3. From the Fig. 3, it is quite clear how the firing angle $\alpha$ is to be fixed and measured.

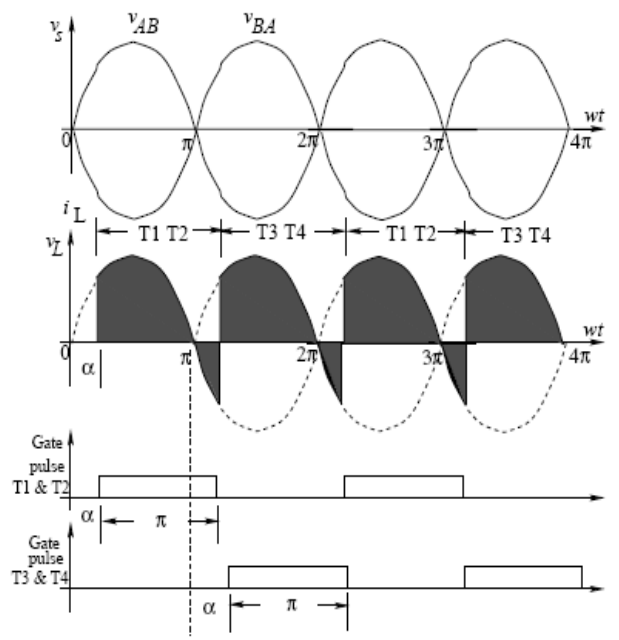

Fig.3. Typical waveforms of a single phase converter

For T1 and T2, $\alpha$ is to be measured from the instant when $\mathrm{V}_{\mathrm{AB}}$ is zero and going towards positive. Similarly $\mathrm{T} 3$ and $\mathrm{T} 4$, $\alpha$ is to be measured from the instant $V_{B A}$ is zero and going towards positive. Thus we see that for successful operation of the fully controlled bridge, the gate pulses to be properly synchronized with the a.c. power supply. It is noted that each thyristor conducts for $180^{\circ}$ only.

\section{Expression for the output voltage}

Assuming the rms value of the supply voltage to be $V_{s}$, the output voltage $\mathrm{V}_{0}$ can be obtained below. The output current has been assumed to be continuous which is true for most of the cases. $\omega$ is the angular frequency of supply a.c. voltage.

$$
\begin{aligned}
V_{o} & =\frac{1}{\pi} \int_{\alpha}^{\alpha+\pi} \sqrt{2} V_{s} \sin \omega t d(\omega t) \\
& =\frac{2 \sqrt{2}}{\pi} V_{s} \cos \alpha \\
\therefore V_{o} & =0.9 V_{s} \cos \alpha
\end{aligned}
$$

\section{E. Popular methods of generating firing pulses}

1) Using ramp signal: In this scheme a ramp signal is generated in synchronism with the a.c. supply. Vs by using two comparators and an approximate ramp generator circuit using a transistor and capacitors as described in Fig. 4.

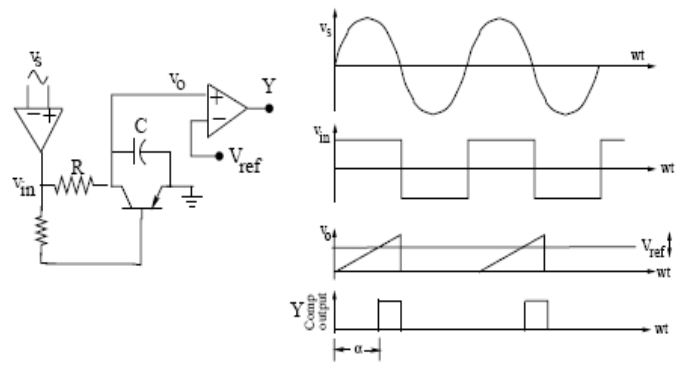

Fig.4. Basic idea of ramp scheme

The first comparator translates the input sinusoidal voltage into a square wave voltage. When the square wave voltage is high, the transistor ( $\mathrm{P}-\mathrm{N}-\mathrm{P}$ type) collector-base junction is forward biased; the transistor is non conducting stage (off) and the capacitor charges exponentially giving ramp rise of the voltage at the output. However, as soon as the square voltage is negative, transistor becomes on due to collector-base junction is reverse biased and the capacitor discharges sharply giving a saw tooth like waveform as shown in Fig. 4. This triangular voltage can now be compared by the second comparator with a variable reference d.c. voltage $\left(\mathrm{V}_{\text {ref }}\right)$ to get the firing pulse signal at $Y$. The value of $\alpha$ can be varied in the range $0^{\circ} \leq \alpha \leq 180^{\circ}$ by changing the value of the reference voltage $\left(\mathrm{V}_{\text {ref }}\right)$.

2) Using cosine control: In this interesting scheme, the supply voltage $\mathrm{V}_{\mathrm{s}}$ is first integrated to obtain a cosine wave as shown in Fig. 5. The cosine wave so obtained is compared with a reference d.c. voltage $\left(\mathrm{V}_{\text {ref }}\right)$. Therefore square pulses will be generated at the output terminal $\mathrm{Y}$ of the comparator. The signal at $\mathrm{Y}$ is synchronized with the pulse and is delayed from the supply zero crossing by an angle $\alpha$. Obviously, the value of $\alpha$ can be varied a range of $0^{0} \leq \alpha \leq 180^{\circ}$

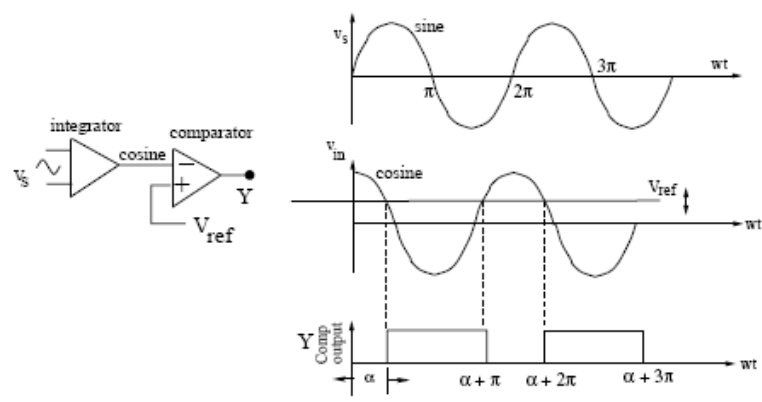

Fig. 5. Basic idea of cosine control scheme.

\section{F. Basic building blocks}

Basic blocks which will be necessary to implement any firing control scheme in a converter circuit are shown in Fig. 6. The figure demonstrates with the help of a single line diagram, the major blocks necessary to generate firing pulses for any scheme. The converter is organized from a.c. power. Since the firing pulses must be synchronized with the a.c. supply, a.c. power also goes to the isolation and synchronizing blocks. Isolation is essential as because the 
control circuit uses very low power devices such as various chips, logic gates etc. The logic circuit block uses few logic gates to implement a particular firing scheme. The strength of the pulse obtained from logic gates may not be sufficient to drive the gate of a thyristor, so amplification of the pulse along with isolation is used at final stage as shown Fig. 6.

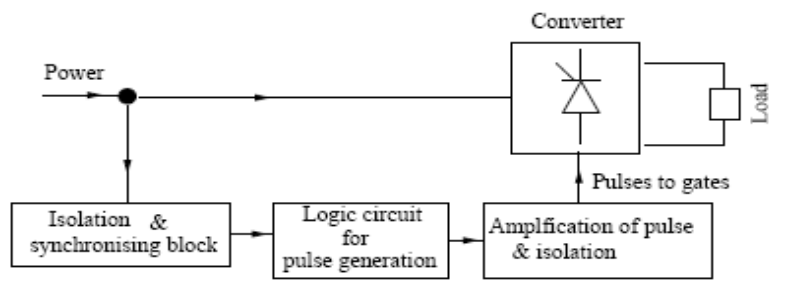

Fig. 6. Basic block of firing control circuit.

\section{Block Diagram REPRESENTATION OF THE COSINE CONTROL SCHEME}

The emphasis of this paper is the implementation of cosine control scheme. We shall first outline the scheme in terms of block diagram and then explain each block in detail. Let $\mathrm{V}_{\mathrm{ab}}$ be the supply voltage feeding the converter for which the control pulses are to be generated. With the help of a step down centre tapped transformer, $\mathrm{V}_{\mathrm{ab}}$ is transformed into two power level voltage $\mathrm{V}_{\mathrm{a} 0}$ and $\mathrm{V}_{\mathrm{b} 0}$. For obvious reason $\mathrm{V}_{\mathrm{a} 0}$ and $\mathrm{V}_{\mathrm{b} 0}$ will be $180^{\circ}$ out of phase as shown in Fig. 7.

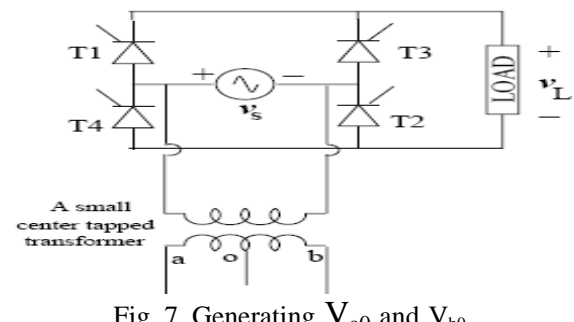

$\mathrm{T} 1 \& \mathrm{~T} 2$ are to be fired when $\mathrm{V}_{\mathrm{a} 0}$ is positive and $\mathrm{T} 3$ \& $\mathrm{T} 4$ are to be fired when $\mathrm{V}_{\mathrm{b} 0}$ is positive. For $\mathrm{T} 1 \& \mathrm{~T} 2$ the firing angle $\alpha$ is to be measured from the instant when $V_{a 0}$ is zero and increasing in the positive direction. The range of variation of $\alpha$ is $0^{0}$ to $180^{\circ}$. Similarly for T3 \& T4 the firing angle $\alpha$ is to be measured from the instant when $V_{b 0}$ is zero and increasing in the positive direction. Basic idea for generating necessary pulses for T1 \& T2 and T3 \& T4 can be understood by referring figures 7,8 and 9 .

With reference to Fig. 8 the signal $\mathrm{V}_{\mathrm{a} 0}$ is integrated with the help of Integrator -1 and a cosine wave will be obtained. This cosine wave is compared with a variable d.c. voltage $\mathrm{V}_{\mathrm{r}}$ using a comparator- 1 .

Noting that $\mathrm{V}_{\mathrm{r}}$ is connected to the +ve terminal of the comparator-1, the output of the comp-1 will be square wave and it goes to high state from the instant when $V_{r}$ becomes greater than the cosine voltage value. However the width of the pulse will vary as $V_{r}$ is varied. Our first aim will be to make the width of the pulse to be $180^{\circ}$. This is achieved in the following way. The output of the Comp-1 is fed to a block mono-1. Output of the mono will be a pulse of small width at positive going edge of the input square wave. The output of mono-1 will thus give small pulses separated by $360^{\circ}$.

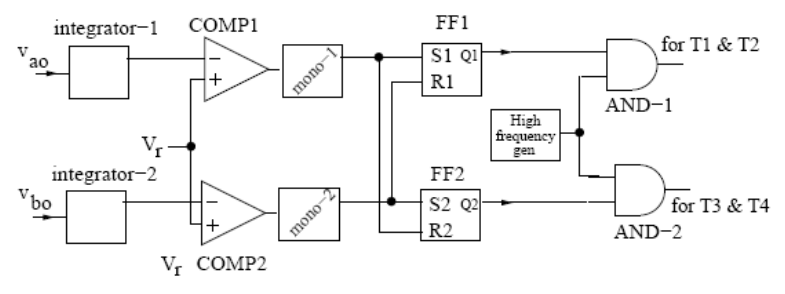

Fig. 8. Basic blocks for cosine control scheme
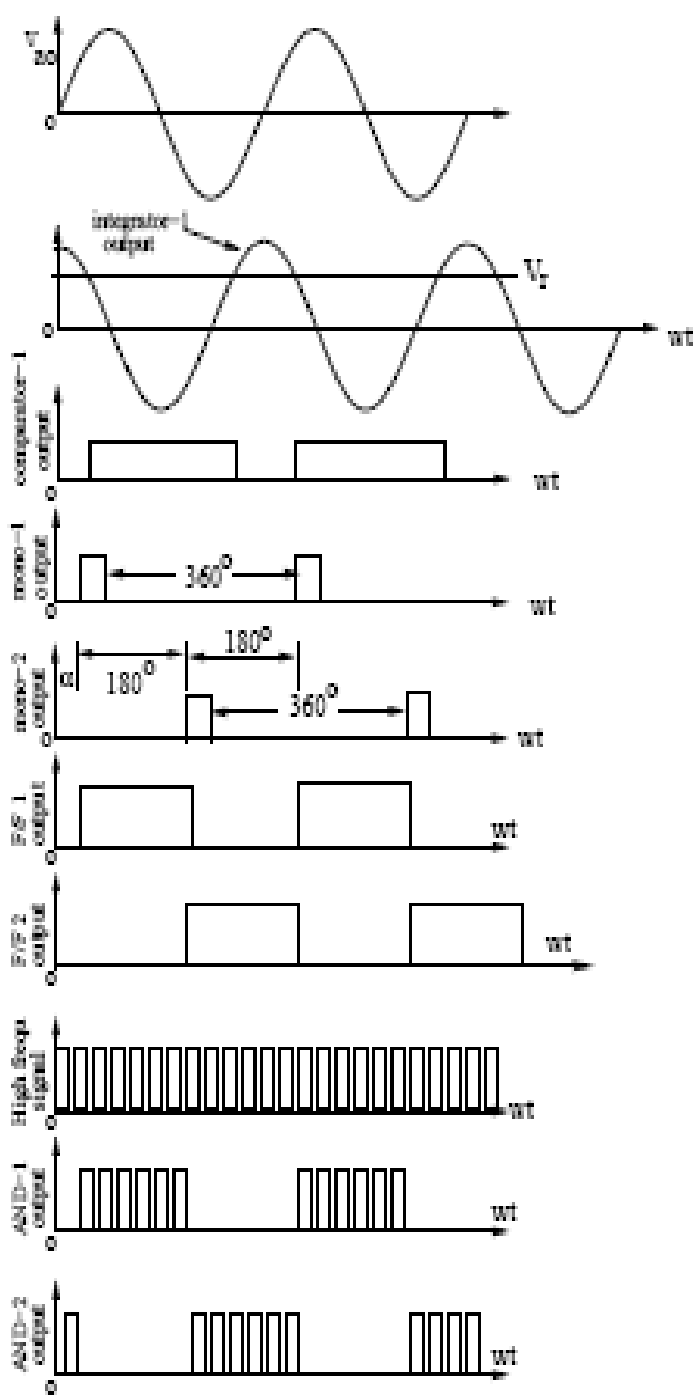

Fig. 9. Waveforms at different points in the circuit of Fig.8

The voltage $\mathrm{V}_{\mathrm{b} 0}$ is similarly processed, i.e., it is integrated then compared with the same variable d.c. with the help of comparator-2, output of COMP-2 will be a square wave and will be shifted by $180^{\circ}$ from the output square wave of COMP-1. This is because of the fact that $\mathrm{V}_{\mathrm{b} 0}$ lags $\mathrm{V}_{\mathrm{a} 0}$ by $180^{\circ}$. The output of the COMP-2 is now fed to a block mono-2. Output of mono-2 will be a pulse of small width at positive going edge of the input square wave.

The output of MONO-2 will thus give small pulses separated by $360^{\circ}$. This is important to know that the fixed width pulse waveforms at the output of mono- 1 and mono-2 are shifted by $180^{\circ}$ as shown in Fig. 9. The outputs of mono1 and mono- 2 can be used in conjunction with to two S-R flip flops so as to generate two square waves each having a fixed width of $180^{\circ}$ and mutually separated by $180^{\circ}$. 


\section{DESCRIPTION OF THE EACH BLOCK}

In this section detail of each block will discussed separately. The type of components used and their connections will also be explained.

\section{A. Input transformer to get $V_{a 0}$ and $V_{b 0}$}

A 220/6-0-6 V $50 \mathrm{~Hz}$ control transformer is selected for the purpose of stepping down the $220 \mathrm{~V}$ supply to a level of 6-0-6 V with the help of the centre tapped secondary as shown in Fig. 10.
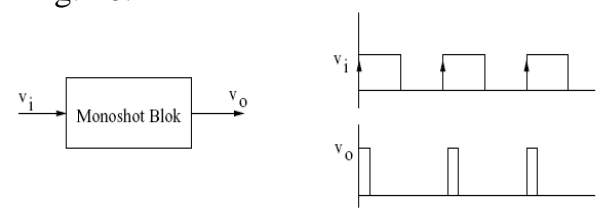

Fig. 10. Input transformer for the control circuit.

\section{B. Integrator to get cosine wave}

Popular IC 741 is used along with some resistor and capacitor to realize integrator function out of it. The values of different circuit parameters are shown in Fig. 11. $\pm 12 \mathrm{~V}$ d.c. supply required for the chip is obtained from a separate d.c. source. The ground point of the d.c. supply is connected to the common ground point zero $(0)$ of the center tapped transformer. Signal $\mathrm{V}_{2} v_{2}=\int v_{a o} d t$. will be obtained as integration of small $\mathrm{V}_{1}$, i.e., For our purpose we will get small $\mathrm{V}_{2} \cdot v_{2}=\int v_{1} d t$.

Another identical integrator is used to integrate $V_{b 0}$ as explained earlier.

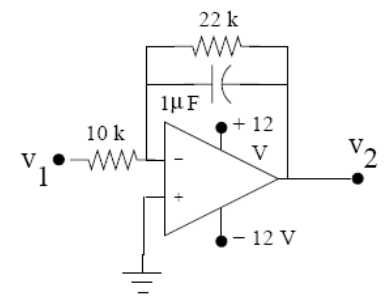

Fig. 11. Integrator using OP AMP 741.

\section{Comparator producing variable width pulse}

An OP AMP (741 IC) is used to realize the comparator block by inverting terminal IC 741, the variable d.c. voltage $\mathrm{V}_{\mathrm{r}}$ is applied to the non inverting terminal or positive terminal, the cosine signal is obtained from the output of the integrator block as connected. $\mathrm{V}_{\mathrm{r}}$ is fed from the output of a $10 \mathrm{~K} \Omega$ variable resistor terminal. The input to the pot is the \pm 12 V supply as shown in Fig 12 .

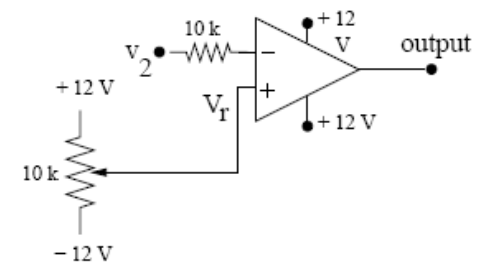

Fig. 12. Comparator using OP AMP IC 741.

\section{Monoshot block using Exclusive OR Gate}

A Monoshot block is supposed to produce thin pulses when the input rectangular input signal $V_{i}$ changes state from 0 to 1 as shown in Fig. 13, a Monoshot block is shown with input signal $\mathrm{V}_{\mathrm{i}}$ and with the desired output signal $\mathrm{V}_{0}$.
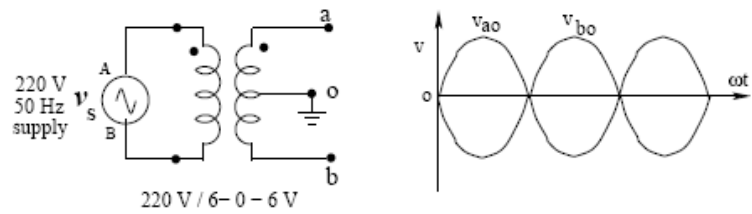

Fig. 13. Characteristics of a Monoshot

In this project work under this paper, the Monoshot is implemented in an interesting way by using Exclusive OR Gate. The truth table and representation of Exclusive OR Gate is shown in Fig. 14. In Exclusive OR gate, the output is high or 1 when one of the inputs is high (1) or odd matching with the others and the output is low or 0 when both the inputs are same or even nature.

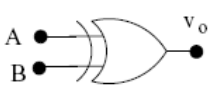

\begin{tabular}{|c|c|c|}
\hline $\mathrm{A}$ & $\mathrm{B}$ & $\mathrm{Y}$ \\
\hline 0 & 0 & 0 \\
0 & 1 & 1 \\
1 & 0 & 1 \\
1 & 1 & 0 \\
\hline
\end{tabular}

Fig. 14. Exclusive OR Gate \& its Truth Table

\section{E. SR Flip flops to get 1800 width pulse}

In the previous section we have seen that the variable width pulse obtain from the comparator output is converted into a train of thin pulses separated by $360^{\circ}$ at the output of the Monoshot in Fig. 15.

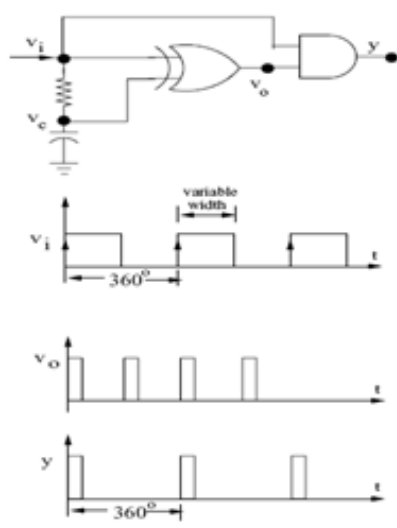

Fig. 15. Final circuit for Monoshot

\section{F. ANDing the rectangular pulse with frequency using 555 timer}

The rectangular voltage signals obtain from the flip flops 1 and 2 are complementary which means separated by $180^{\circ}$ as desired. In our case where the supply frequency is $50 \mathrm{~Hz}$, the time period of the signals will be $20 \mathrm{~ms}$ and for $10 \mathrm{~ms}$ it will remain high and for rest of the $10 \mathrm{~ms}$ it will be low. Outputs of the flip flops cannot however, be connected directly to between the gate and cathode of a thyristor, and because the output from a TTL (Transistor-Transistor-Logic) chip will not be able to supply the necessary current required by the gate circuit of a thyristor. Apart from this, we require isolation between the control circuit and power circuit. Therefore with the help of a transistor and a pulse transformer these two objectives of strengthening the pulse and providing the isolation are met. The idea is depicted in 
Fig. 16.

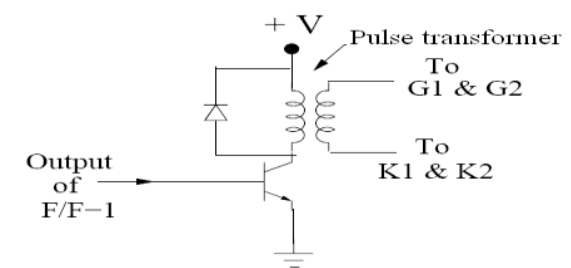

Fig. 16. Showing amplification \& isolation circuit.

\section{G. Complete circuit diagram}

Putting all the blocks together, the complete connection with circuit diagram of the circuit is shown in Fig. 29 at the end.

\section{H. $\quad \pm 12$ V Power supply circuit}

As seen from the circuit shown in Fig. 17 a $\pm 12 \mathrm{~V}$ d.c. power supply is required for supplying various chips used. To make the set up self content, standard power supply chips of numbers IC 7812 and IC 7912 are used in conjunction with a centre tapped transformer, diode bridge rectifier and filter capacitors as shown in Fig. 17.

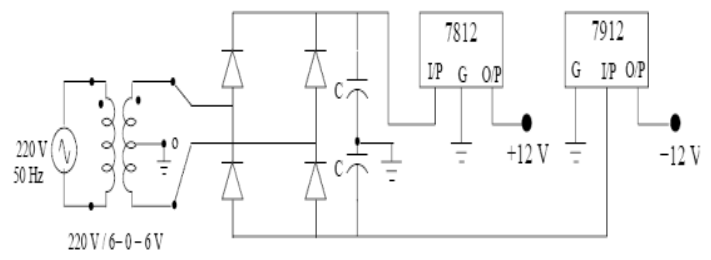

Fig. 17. Circuit for \pm 12 V Power supply.

\section{Methodology For The Proposed Work}

\section{A. Description for IC chips used:}

The following things are elaborated for the method using:

i. IC 4043 is used for realizing SR flip flop. In this chip 4 separate SR flip flops are available. This chip works with a d. c. supply of $+3 \mathrm{~V}$ to $+15 \mathrm{~V}$. In our case power supply used is $+12 \mathrm{~V}$. The chip has 16 pins as shown in Fig 18 .

ii. IC 4081 is used for realizing AND gate. In this chip 4 separate AND gates are available. This chip works with a d.c. supply range of $+3 \mathrm{~V}$ to $+15 \mathrm{~V}$. In our case power supply used is $+12 \mathrm{~V}$. The chip has 14 pins as shown in Fig. 19.

iii. IC 4070 is used for realizing Ex-OR gates. In this 4 separate Ex-OR gates are available. This chip works with a d.c. supply range of $+3 \mathrm{~V}$ to $+15 \mathrm{~V}$. In our case power supply used is $+12 \mathrm{~V}$. The chip has 14 pins as shown in Fig 20.

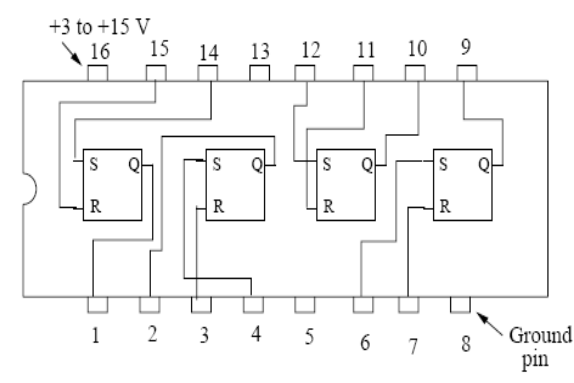

Fig- 18 Pin description of IC 4043

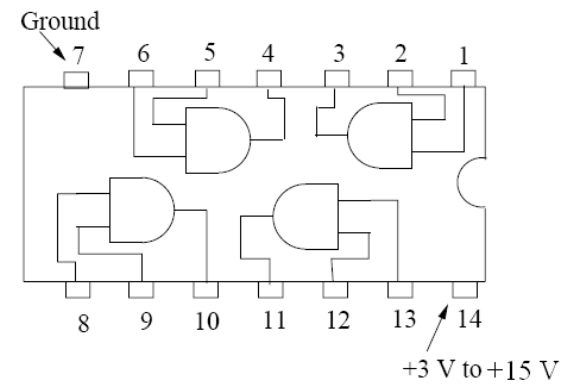

Fig. 19. Pin descriptions IC 4081

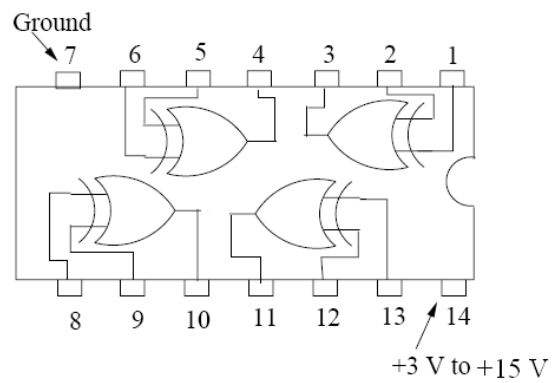

Fig. 20. Pin descriptions IC 4070

\section{B. Components used}

The followings components are used for the circuit:

i. Two centre tapped transformer: $220 \mathrm{~V} / 6-0-6 \mathrm{~V}$.

ii. Two IC 741 OP AMP for two integrators one corresponding to $\mathrm{V}_{\mathrm{a} 0}$ and the other corresponding to $\mathrm{V}_{\mathrm{b} 0}$.

iii. Two IC 741 OP AMP for two comparators.

iv. One IC 4070 which houses 4 EX-OR gates.

v. One IC 4081 which houses 4 AND gates.

vi. One IC 4043 which houses 4 SR flip flops gates.

vii. One 555 timer for generating high frequency pulses.

viii. Number of resistors and capacitors of various values as detailed shown in the circuit.

ix. Few diodes for making the $\pm 12 \mathrm{~V}$ power supply and also to clip the negative half of rectangular pulse obtained at the output of the comparator.

$\mathrm{x}$. One $10 \mathrm{~K} \Omega$ pot for having variable d.c. voltage $\mathrm{V}_{\mathrm{r}}$

xi. Two rectangular power supply chips numbered IC 7812 and IC 7912 for \pm 12 V supply.

\section{EXPERIMENTAL RESULTS}

The circuit fabricated is tested for important waveforms at various points. The primary of the input isolation transformer is energized with $220 \mathrm{~V}, 50 \mathrm{~Hz}$ source. The secondary output voltages of $\mathrm{V}_{\mathrm{a} 0}$ and $\mathrm{V}_{\mathrm{b} 0}$ are recorded in an oscilloscope and shown in Fig. 21.

As told earlier the signal $\mathrm{V}_{\mathrm{a} 0}$ is integrated to obtain $\int V_{a 0} \mathrm{dt}$ with the help of an IC 741 op amp, i.e., if $\mathrm{V}_{\mathrm{a} 0}=\mathrm{V}_{\max } \cos \omega \mathrm{t}$. The obtained waveforms at the input and output of the integrator are shown in Fig. 22. In Fig. 23 the output waveforms of comparator and Exclusive OR gates are shown. 


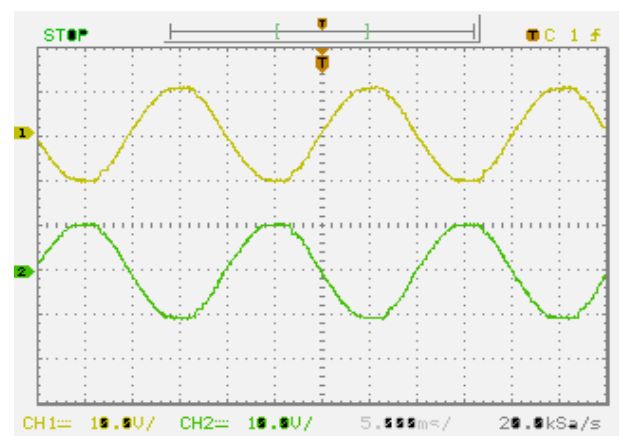

Fig. 21. Waveforms of $\mathrm{VaO}$ and $\mathrm{Vb} 0$

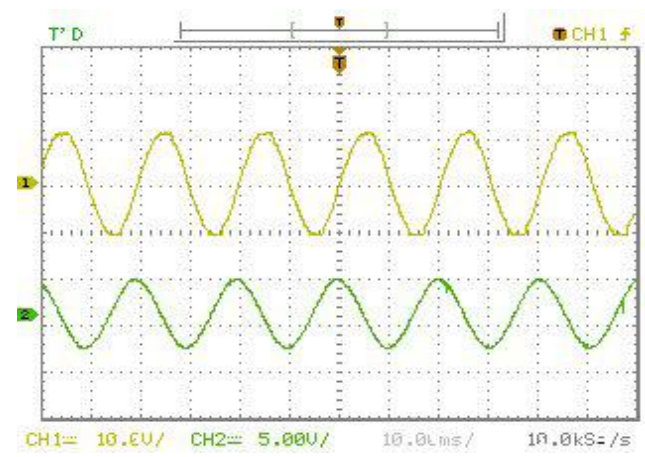

Fig. 22. Waveforms $\mathrm{V}_{\mathrm{a} 0}$ and $\int_{\mathrm{a}_{0}} \mathrm{dt}$

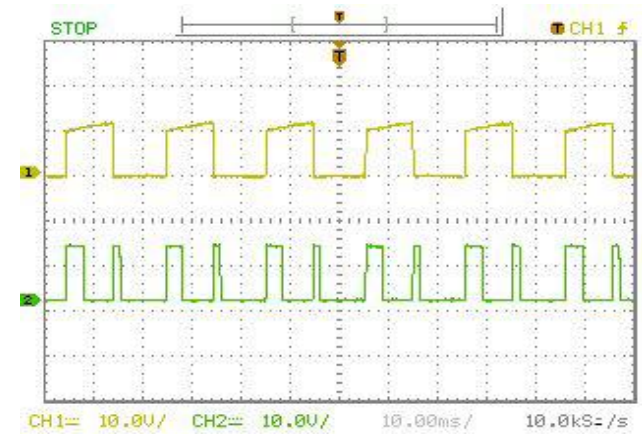

Fig. 23. Output of Comparator and EX-OR gate

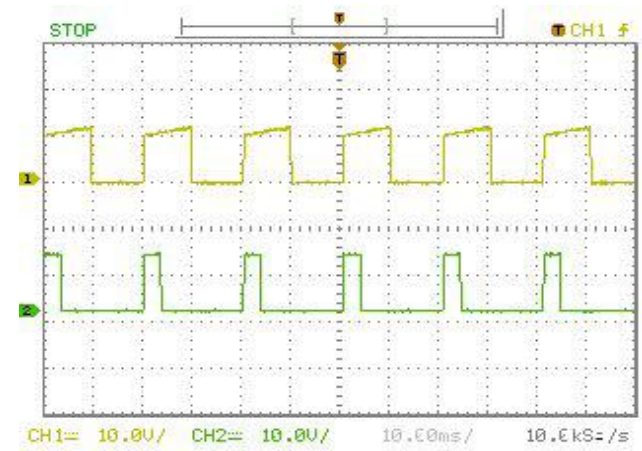

Fig. 24. Output of Comparator and first AND gate.

It can be noted that we get train of thin pulses both at the positive and negative edge of the comparator square wave output as explained. Since our intention is to obtain thin pulses only at the positive edges, output of the XOR gate is ANDed with the comparator output voltage as detailed in earlier sections which is given in Fig. 24.

We know the output of the SR Flip Flop will give square pulses of width $180^{\circ}$, i.e., $10 \mathrm{~ms}$. However such a wide pulse is not suitable for a pulse transformer as explained. So this wide width continuous pulse is converted into chopped pulses by ANDing the output of SR Flip Flop and the output of 555 timer chip connected in astable mode. In Fig. 25 the output of the SR Flip Flop and the output of 555 timer chip are shown. In Fig. 26 output of the SR Flip Flops are ANDed with the output of 555 timer chips. It can easily be seen that after ANDing the continuous wide pulse become thin pulse in nature.

The final waveforms of getting two complementary separated by $180^{\circ}$ widths chopped pulses one corresponding to $\mathrm{V}_{\mathrm{a} 0}$ and another to $\mathrm{V}_{\mathrm{b} 0}$ are shown in Fig. 26. In fact these two complementary signals are the gate signals of the thyristors.

To demonstrate at what firing angle $\alpha$ the bridge is operating, the waveforms of $\mathrm{V}_{\mathrm{a} 0}$ and the final pulses synchronized with $\mathrm{V}_{\mathrm{a} 0}$ are shown in Fig 27.

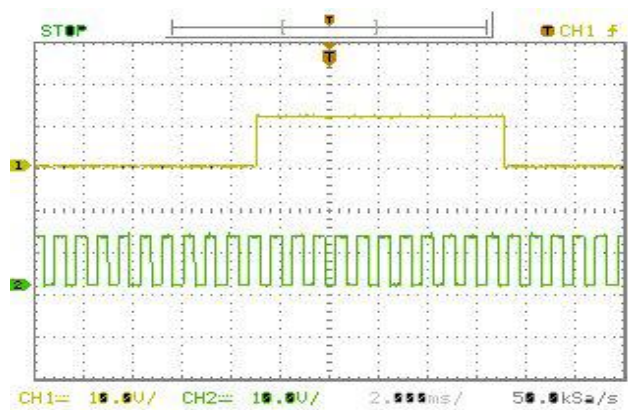

Fig. 25. Output of SR Flip Flop and 555 timer chip

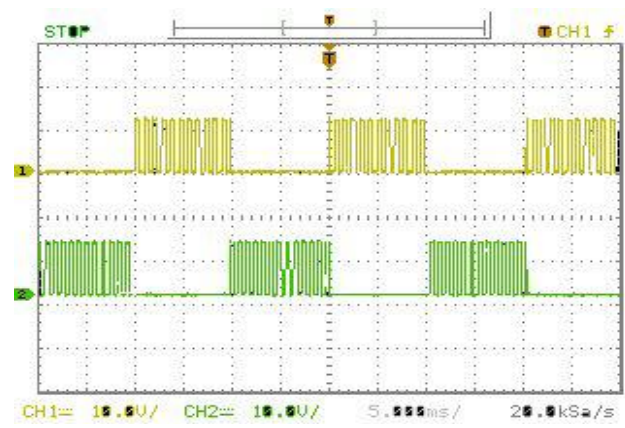

Fig. 26. Final gate pulses for thyristors.

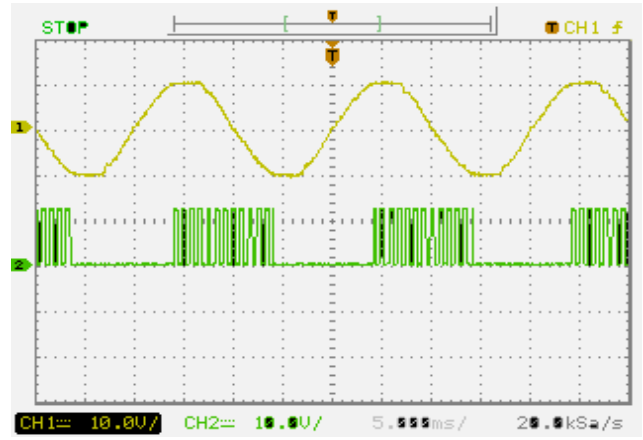

Fig. 27. Waveforms of the measuring angle $\alpha$.

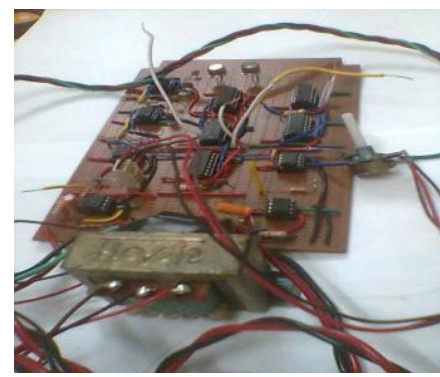

Fig. 28. Practical firing circuit 


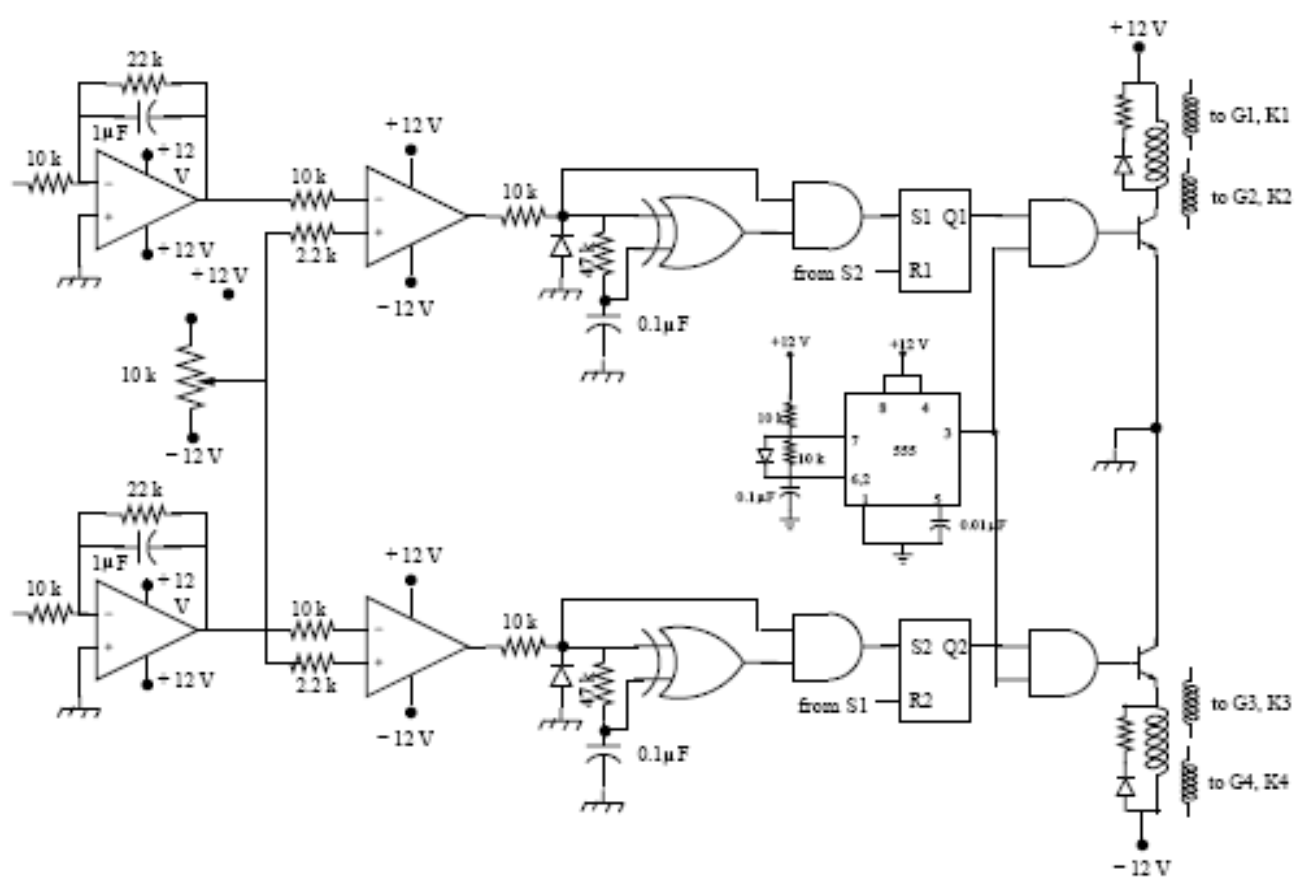

Fig. 29. Complete circuit diagram of cosine control scheme for firing circuit of single-phase converter.

\section{CONCLUSION}

In this project work an attempt has been made to implement and test a firing circuit for a fully controlled single phase converter. The circuit is fabricated using components such as resistors, capacitors and some standard IC chips. The circuit is first fabricated on bread board and then tested. Now from all of this, following conclusions can be drawn that cosine control scheme for firing circuit is studied and understood. Various blocks necessary to implement the scheme are decided. We procure the relevant ICs and electronics components. This is done in a correct way for implementing in the circuit. The circuit successfully generated complementary pulses as desired and the waveforms recorded for future realistic studies.

\section{REFERENCES}

[1] P.C. Sen, Modern Power Electronics, Wheeler Publishing, 1998

[2] Muhammad H. Rashid, Power Electronics, Prentice Hall of India Publishers Ltd, 2009.

[3] Philip T. Krein, Elements of Power Electronics, Oxford University Press, 2003.

[4] Paul B. Zbar and Albert P. Malvino, Basic Electronics: A Text - Lab Manual, $5^{\text {th }}$ edition, Tata McGraw-Hill Publisher, 2005.

[5] O.P Arora, Power Electronics Laboratory: Experiments \& Organization, $1^{\text {st }}$ edition, Wheeler Publishing, 1993.

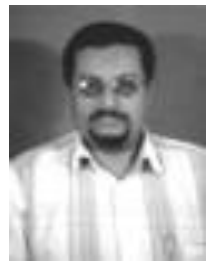

Mr. Tirtharaj Sen is an Assistant Professor in the Department of Electrical Engineering, Asansol Engineering College, Kanyapur, Vivekananda Sarani, Asansol, Burdwan-713305, India. He obtained his B.E. (Electrical), M-Tech. (Electrical Power) both from Calcutta University and pursuing $\mathrm{PhD}$ at Jadavpur University. He has twelve years Industrial experience in Hindustan Motors Limited (1989-2001). He was an Ex Assistant Professor \& Head, Dept. of E.E, Bengal Institute of Technology and Management, Santiniketan. (2005-2010). He has a number of publications [Both in Journals \& in Proceedings of Conferences, National \& International]. He is a member of Institution of Engineers (India) and IEEE. His research interests are in Noise Pollution, Harmonics and Non Conventional Energy.

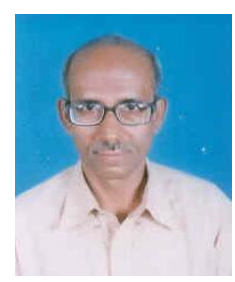

Dr. Pijush Kanti Bhattacharjee is associated with the study in Engineering, Management, Law, IndoAllopathy, Herbal, Homeopathic \& Yogic medicines. He is having qualifications M.E., MBA, MDCTech, AMIE (BE or BTech), B.Sc.(D), BIASM, CMS, PET, EDT, FWT, DATHRY, B.A., LLB, KOVID, DH, ACE, FDCI etc. He had started service in Government of India, Department of Telecommunications (DoT) since 1981 as a Telecom Engineer, where he worked upto January 2007 (26 Years), lastly holding Assistant Director post at Telecom Engineering Centre, DoT, Kolkata, India. Thereafter, he worked at IMPS College of Engineering and Technology, Malda, WB, India as an Assistant Professor in the Department of Electronics and Communication Engineering from January 2007 to February 2008, from Feb 2008 to Dec 2008 at Haldia Institute of Technology, Haldia, WB, India, from Dec 2008 to June 2010 at Bengal Institute of Technology and Management, Santiniketan, WB, India and June 2010 to Aug 2010 at Camellia Institute of Technology, Kolkata, India. $\mathrm{He}$ joined in Assam University (A Central University), Silchar, Assam, India in Sept 2010 at the same post and department. He has written two books "Telecommunication India" \& "Computer". He is a Member of IACSIT, Singapore; CSTA, USA; IAENG, Hongkong; and IE, ISTE, IAPQR, IIM, ARP, India. His research interests are in Telecommunications including Mobile Communications, Image Processing, VLSI, Nanotechnology, Management and Environmental Pollution etc.

Ms. Manjima Bhattacharya is a Lecturer in Electrical Engineering Department at Murshidabad College of Engineering \& Technology, Berhampore, West Bengal, India. She has passed B. Tech in Electrical Engineering from West Bengal University of Technology, Kolkata, West Bengal,India 